\title{
“NADA ENCUENTRO DE QUE DEBA AVERGONZARME": EL EXILIO AFRANCESADO DE MARIANO LUIS DE URQUIJO
}

\author{
Aleix Romero Peña \\ UNIVERSIDAD DE LA RIOJA
}

\begin{abstract}
RESUMEN: Apenas llegaron a cuatro los años que Mariano Luis de Urquijo estuvo en el exilio (1813-1817), hasta su temprana muerte, pero resulta un periodo de especial interés por su capital contribución a la defensa de los afrancesados. En el presente artículo estudiaremos el contexto de la persecución que sufrió, su participación en la literatura afrancesada y la imagen póstuma que, en consonancia con la anterior, fabricó su entorno sobre él.
\end{abstract}

PALABRAS CLAVE: Mariano Luis de Urquijo, exilio, afrancesado, Juan Antonio Llorente, Fernando VII.

\section{“NADA ENCUENTRO DE QUE DEBA AVERGONZARME": THE AFRANCESADO EXILE OF MARIANO LUIS DE URQUIJO}

\begin{abstract}
Mariano Luis de Urquijo just lived four years in the exile (1813-1817), until his early death. However, this is a very interesting period, because Urquijo contribution to the defense of the afrancesados. In this article, we will study the context of the Urquijo's persecution, his involvement in afrancesada literature and, in line with previous, his posthumous image settled by his social circle.
\end{abstract}

KEY WORDS: Mariano Luis de Urquijo, exile, afrancesado, Juan Antonio Llorente, Fernando VII.

Recibido: 23-05-2103/Aceptado: 12-09-2013 


\section{INTRODUCCIÓN: UNA CONCIENCIA TRANQUILA}

La primera frase del título forma parte de un conocido párrafo que Mariano Luis de Urquijo incluyó en una carta escrita a un amigo anónimo en 1816; recogido posteriormente para el elogio póstumo del personaje, dice exactamente así:

Yo me examino: [...] la conciencia habla al hombre à sus solas. En el silencio de la noche, quando el sueño no viene, repaso mi vida; y nada encuentro de que deba avergonzarme, ni como hombre publico, ni como ciudadano español. Esta tranquilidad de conciencia me hace superior à las injusticias y à las proscripciones ${ }^{1}$.

Las palabras anteriores constituyen toda una declaración de intenciones: casi al final de sus días, el emigrado ${ }^{2}$ Urquijo, antiguo ministro secretario de Estado con José I, no mostraba arrepentimiento de ningún tipo por haber abrazado la causa política que le llevaría a abandonar España y a sufrir la confiscación de sus bienes. La idea se convirtió a su muerte en una especie de tópico, que se resume en la imagen de Urquijo sobreponiéndose a las penurias de la emigración mediante una vida retirada, presidida por la "calma inalterable del justo"3.

No podemos asegurar que Urquijo viviera sus últimos años con la conciencia tranquila. Las apelaciones al estoicismo son un tópico literario que en el género apologético deviene en lo que se ha denominado "coartada senequista". Se trata por tanto de una proyección interesada, en línea con la empresa literaria afrancesada del exilio, que en determinados casos - como los de Francisco Amorós, Miguel José de Azanza y Gonzalo O’Farrill, José María Carnerero o Félix José Reinoso-, se planteó como una batalla por convencer a la opinión pública ${ }^{5}$. En este sentido, las explicaciones que se dan sobre el comportamiento de Urquijo, y que aparecen en obras como las Memorias para la historia de la

\footnotetext{
${ }^{1}$ BERAZA, Antonio de: Elogio de D. Mariano Luis de Urquijo, ministro-secretario de Estado de España, París, L-E Herhan, 1820, p. 74.

${ }^{2}$ Empleo la voz emigrado como sinónimo de exiliado, pues ambas dan cuenta de la misma realidad; soy también consciente de que el segundo constituye para la época estudiada un anacronismo conceptual. Sobre esto último véase FUENTES, Juan Francisco: "Imagen del exilio y del exiliado en la España del siglo XIX", Ayer, n 47 (2002), p. 35; y FERNÁNDEZ SIRVENT, Rafael: "París, destino privilegiado del exilio español. A propósito de varias aportaciones historiográficas recientes", Pasado y Memoria, no 9 (2010), pp. 192-193

${ }^{3}$ BERAZA, A. de: Elogio..., op. cit., p. 74.

${ }^{4}$ Véase al respecto el estudio introductorio de Gabriel Sánchez Espinosa en Memorias del ilustrado aragonés José Nicolás de Azara, Zaragoza, Institución Fernando el Católico, 2000.

${ }^{5}$ Las obras iban dirigidas principalmente hacia un público español, pues era el propio colectivo de emigrados el que las recibía con mayor interés, aunque también tuvieron repercusión en España. Algunos libros llegaron a alcanzar una tirada de un millar de ejemplares. LÓPEZ TABAR, Juan: Los famosos traidores. Los afrancesados durante la crisis del Antiguo Régimen, Madrid, Biblioteca Nueva, 2001, pp. 135-142.
} 
revolución española o el Elogio funerario de D. Mariano Luis de Urquijo, contienen argumentos retorcidos y silencios elocuentes.

A pesar de todo lo anterior, resultaría injusto negarles a priori su valor como documento histórico. Urquijo manejaba datos suficientes como para realizar una defensa política de la conducta observada por él durante la Guerra de la Independencia, o, mejor dicho, de las razones de su participación el gobierno josefino, que era la principal acusación esgrimida contra él por la España fernandina. Lejos de pretender realizar un juicio histórico sobre decisiones dramáticas, las siguientes páginas están dedicadas a presentar sus argumentos y comprobar qué correspondencia guardan con el relato de los hechos.

\section{URQUIJO FRENTE A LOS HOMBRES DE FERNANDO VII}

Mariano Luis de Urquijo (1769-1817) fue un burócrata ilustrado, uno de tantos intelectuales orgánicos que florecieron en los reinados de Carlos III y Carlos IV. Gracias a la protección de Manuel Godoy consiguió escalar puestos en la Administración real hasta llegar a la dirección de la Secretaría de Estado, la institución de gobierno más importante de la Monarquía borbónica, donde se mantuvo por espacio de algo más de dos años, desde 1798 hasta 1800. Por cuestiones que ya hemos expuesto en otros trabajos ${ }^{6}$ y que ahora no interesa detallar, fue cesado de su cargo, en una caída que tuvo todos los aires de una desgracia, y sufrió un proceso que culminó en un confinamiento. La amnistía hubo de esperar al motín de Aranjuez y la entronización de Fernando VII, como sucedió con otros tantos que se habían enquistado a ojos de los reyes Carlos y María Luisa y Godoy, la famosa Trinidad en la tierra.

Con bastante seguridad las medidas de gracia de Fernando obedecieron más al deseo de desquite y a la necesidad de ganarse partidarios que a la intención de hacer justicia ${ }^{7}$. La presencia en la camarilla más próxima al monarca de personajes como Pedro Cevallos, primo político de Godoy y sucesor de Urquijo en la dirección de la Secretaría de Estado, alimenta el escepticismo sobre la posibilidad de una rehabilitación política. El desinterés y el recelo que despertaba su persona entre las filas fernandinas se pusieron en evidencia cuando Urquijo se trasladó a Vitoria para convencer a Fernando VII de no partir al encuentro de Napoleón.

\footnotetext{
${ }^{6}$ ROMERO PEÑA, Aleix: "Caída y persecución del ministro Urquijo y de los jansenistas españoles”, Revista Historia Autónoma. Revista multidisciplinar de la Asociación Historia Autónoma, no 2, 2013, pp. 75-91.

7 LA PARRA, Emilio: "El mito del rey deseado", en C. Demange et alii (dirs.): Sombras de mayo. Mitos y memorias de la Guerra de la Independencia en España (1808-1814), Madrid, Casa Velázquez, 2007, pp. 228-229.
} 
Del relato de aquellos hechos sólo disponemos del testimonio del propio Urquijo, posiblemente adulterado, según el cual los hombres del séquito fernandino se mostraron inflexibles en su determinación de partir a Bayona ${ }^{8}$. Sólo es citado por su nombre el duque del Infantado; de Juan Escóiquiz dice que estaba enfermo, mientras que el nombre de Cevallos es cuidadosamente omitido. La impresión producida por las gentes de confianza de Fernando VII fue desastrosa y Urquijo afirma en su narración: "en mi opinión todos están ciegos, y caminan à una ruina inevitable”.

El segundo encuentro con los hombres de Fernando se produciría dos meses después en Bayona, en un contexto radicalmente distinto. Fernando y su padre ya habían renunciado al trono de España y comenzaban a prepararse los primeros borradores de la Constitución de Bayona. Urquijo ha sido invitado por Napoleón a adherirse a la causa de su hermano José, y entre sus primeras tareas figuraría la de recabar la opinión de algunos de los integrantes del cortejo del antiguo rey de España. Un emocionado Infantado observaba ante las preguntas de Urquijo que se había quedado en la ciudad francesa para servir y ser útil ${ }^{9}$ Y Y ciertamente que lo fue, pues asistió con asiduidad a las sesiones de la Asamblea de Notables que habrían de aprobar la Constitución de Bayona y selló su ratificación con una firma ${ }^{10}$. Cevallos aún fue más allá y acabó como ministro de Negocios Extranjeros.

A comienzos de julio de 1808, mientras el depuesto Fernando se hallaba en su cómodo retiro de Valençay, José I atravesaba la frontera para hacerse cargo del reino; no habría pasado ni un mes cuando la situación tomó un nuevo giro. La inesperada derrota del mariscal Dupont en Bailén y la frialdad con que el nuevo soberano fue acogido por sus súbditos hicieron aflojar las fidelidades levemente anudadas en Bayona. Cuando José I ordenó la evacuación de Madrid, muy pocos de los que entraron con él en la península le siguieron. Los Grandes de España, la mayoría de los cuales había sido admitida entre la servidumbre cortesana, abandonaron a su rey, al igual que muchos funcionarios, oficiales, consejeros de Estado, militares e incluso dos ministros del gobierno, Cevallos y Sebastián Piñuela.

Urquijo fue de los que partieron, dejando atrás amigos y enemigos. Nunca perdonó, dejándose llevar por un rencor que recorre todos los escritos de esta etapa. Como sabiamente apunta Jean-Philippe Luis, durante la guerra saltaron por los aires los antiguos

\footnotetext{
${ }^{8}$ Urquijo a Cuesta. Bilbao, 13-IV-1808. NELLERTO: Memorias para la historia de la revolución española, París, M. Plassan, 1814, t. II, nº XXIV, pp. 89-102.

${ }^{9}$ Urquijo a Cuesta. Bayona, 5-VI-1808. Ibidem, no LXVII, p. 218.

${ }^{10}$ LA PARRA, Emilio: “Los hombres de Fernando VII en 1808”, en A. Alberola y E. Larriba, (eds.): Las élites de España y la "revolución de España". Estudios en homenaje al profesor Gérard Dufour, Alicante, Publicaciones de la Universidad de Alicante, 2010, pp. 136-138.
} 
lazos clientelares ${ }^{11}$. Nadie mejor que Urquijo para ponerlo de manifiesto. En una carta escrita al ultramontano obispo de Orense, Pedro Quevedo Quintano, se quejaba recordaba que los Borbones, con su "vergonzosa traición" - "lâche défection"- habían roto los pactos solemnes que les unían a los españoles ${ }^{12}$ : de esta manera reivindicó su patriotismo frente a los insurgentes, a quienes consideraba manipulados por fuerzas oscuras. Fue de los que más aplaudieron los decretos otorgados por Napoleón en diciembre de 1808, después de la toma de Madrid, que pusieron punto y final al espíritu de concordia de la Constitución de Bayona $^{13}$. No resulta extraño que José I decidiera encargarle la redacción de artículos para la Gazeta de Madrid sobre la liquidación de la deuda pública, la cesación de los antiguos empleados, la supresión de los Consejos y Juntas o la eliminación de grandezas y títulos de Castilla $^{14}$ : era un entusiasta defensor de tales providencias.

Resultaría simplista ver en todo lo anterior el producto de una venganza, pero es evidente que las motivaciones emocionales también pesaron a la hora de apoyar un giro más reformista y, a la vez, más represivo. Urquijo no sólo había roto con unas personas, sino que mostraba públicamente su rechazo hacia las instituciones - "instituciones odiosas"- del Antiguo Régimen y el sistema - "sistema funesto"- de la Monarquía borbónica $^{15}$, a las que había estado vinculado personalmente.

\section{LA PERSECUCIÓN}

Su actuación política al frente de la Secretaría de Estado y su significación como reformista habían convertido a Urquijo en una diana de los sectores ultramontanos, que desde 1800 le denigraban como "enemigo de la religión"16. En los tumultuosos días de julio de 1808, una vez se hubiese difundido su nombramiento como ministro secretario de Estado, el antiguo jesuita expulso Manuel Luengo recogía en su diario la estupefacción que le provocaba la

\footnotetext{
11 "Los afrancesados, una cuestión abierta", Ayer. Dossier dedicado a la Guerra de la Independencia, no 86, 2012, pp. pp. 108-109.

12 Urquijo al obispo de Orense, París, 8-IX-1808. Mémoires et correspondance politique et militaire du roi Joseph I, publiés, anotés e mis en ordre par A. Du Casse, París, Perrotin, 1853-1854, t. V, p. 60.

13 ARTOLA, Miguel: Los afrancesados, Madrid, Alianza, 1989, p. 116.

${ }^{14}$ Los artículos sobre liquidación de la deuda pública aparecen en la Gazeta de Madrid no 164, 12-VI-1809, pp.

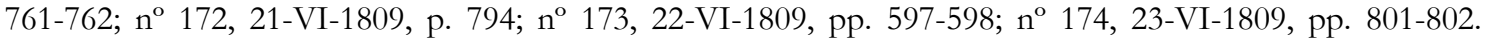
Cesación de antiguos empleados en Gazeta de Madrid no 247, 3-IX-1809, pp. 1095-1096; n 248, 4-IX-1809, pp. 1099-1100; n 249, 5-IX-1809, p. 1104. Supresión de Consejos y Juntas en Gazeta de Madrid no 250, 6-IX1809, pp. 1107-1108; n 252, 8-IX-1809, pp. 1115-1116. Eliminación de grandezas y títulos en Gazeta de Madrid no 254, 10-IX-1809, pp. 1123-1124; n 255, 11-IX-1809, p. 1128; no 256, 12-IX-1809, p. 1132; n 257 , 13-IX-1809, pp. 1135-1136.

15 "Continúa el discurso de ayer relativo al decreto de S. M. de 9 de este mes". Gazeta de Madrid, no 173, 22VI-1809.

${ }^{16}$ Aunque en su desgracia importara más el continente que el contenido. Véase el artículo citado en la nota 5.
} 
noticia: la presencia en el gabinete josefino del que calificaba como "filósofo incrédulo, o por lo menos hereje", era la prueba irrefutable de la inconsecuencia de José I, que se había vanagloriado ante los españoles de su catolicismo. Además aquello indicaba que las abdicaciones de Bayona habían sido el resultado de una gran conspiración urdida por los franceses con la colaboración de "españoles jansenistas, francmasones y filósofos", que estaban repartidos por todos los estratos de la sociedad ${ }^{17}$.

La tesis conspiratoria se generalizó en el bando patriota. Tras la primera evacuación josefina de Madrid a finales de julio de 1808 cuando la Junta Suprema Central decidió formar una causa contra los seis ministros que enviaron a su presidente el conde de Floridablanca, al decano del Consejo Real y al corregidor de Madrid tres cartas idénticas para que se adhirieran al bando de José I. "Altamente indignado" al comprobar la firma de los autores -Azanza, O’Farrill, Manuel Romero, Urquijo, Arribas y el conde de Cabarrús-, el anciano Floridablanca ordenó que las cartas fueran quemadas por el verdugo y que la Real Sala de Alcaldes incoase causas contra ellos, declarándoles: "abandonados à la execracion publica, tenidos pr. infidentes, desleales y malos servidores a su legitimo Rey; indignos del nombre [de] Español y traidores à la Religion, à la Patria y al Estado"18. Una manifestación muy dura y poco condescendiente para unos hombres a las que tanto conocía bien por su cercanía a los cenáculos de poder; especialmente injusta el caso de Urquijo, de quien ya sabemos que trató de impedir el viaje de Fernando a Bayona.

El episodio de Vitoria no era en aquellos momentos de dominio público. Para la prensa y los diputados patriotas, sobre todo los más cercanos a las posiciones absolutistas, lo que subrayaban los hechos era la colaboración de Urquijo con el invasor, que interpretaban como una desnaturalización que se explicaban por su afrancesamiento cultural. Urquijo como tantos otros josefinos, no se sentía español. El Despertador políticocristiano publicaba en 1808 ó 1809 que:

Los Godoyes, Fuentes, Urquijos, Azanzas, Marquinas, Negretes, Mazarredos, Frías, Izquierdos, Duros, Ofarriles, Espeletas, y demás afrancesados y afilosofados que hay en España, son naturalmente franceses, aunque no estén ni hayan nacido en Francia ${ }^{19}$.

\footnotetext{
17 LUENGO, Manuel: 1808. El año de la conspiración, edición de Enrique Giménez López e Inmaculada Fernández Arrillaga, Alicante, Publicaciones de la Universidad de Alicante, 2010, p. 308.

18 "Sobre las cartas cogidas por las avanzadas de Somosierra firmadas por los malos Españoles que sirven al enemigo". 24-XI-1808. AHN, Estado, leg. 29 H. Sección de Gracia y Justicia. Expedientes de denuncias y delaciones por infidencia.

${ }_{19}$ Reproducido en MORANGE, Claude: “¿Afrancesados o josefinos?”, Spagna contemporanea, n⿳ 25, 2005, p. 36.
} 
El diputado y eclesiástico Blas de Ostolaza, confesor de Fernando VII y ferviente defensor de su causa, resumió a la perfección esta cruzada contra el afrancesamiento al afirmar en una sesión de Cortes de 1811 que había sido "esta manía de parecernos á los franceses" la que había originado "tantos eruditos a la violeta, tantos traidores a la patria y tantos débiles" ${ }^{20}$. El afrancesado era aquel cuyas ideas le convertían en potencialmente traidor a su patria, incluso por encima del bando al que se adscribiese. En el caso de los josefinos esta asimilación empezó a generalizarse avanzada la contienda, aun cuando supusiera un reduccionismo absurdo de un complejo fenómeno cultural que fue fraguándose en el reinado de Carlos III $^{21}$.

Una vez tomado definitivamente Madrid por los patriotas, la Hacienda pública procedió a confiscar y a tomar en propiedad los bienes de Urquijo por su condición de ministro del rey Intruso. Conviene saber que, al igual que otros notables josefinos, se había enriquecido con la desamortización de los bienes nacionales, procedentes de las confiscaciones de propiedades religiosas y de emigrados a la zona patriota, adquiriendo varias casas en Madrid y Bilbao, así como dehesas en la provincia de Toledo ${ }^{22}$. En la capital habitaba un fastuoso palacio en la Plazuela del Ángel, a donde acudió el 22 de julio de 1813 el agente de Hacienda Carlos Máximo Fernández de Rivera, acompañado por el alcalde del Barrio de la Cruz Juan José Ojanguren, dos hombres buenos y el alguacil, con el propósito de hacer un inventario de los bienes que se hallasen en la misma.

Durante la visita se encontraron con algunos albañiles que estaban realizando obras por órdenes del jefe político de Madrid, Joaquín García Doménech, que pretendía instalarse en la vivienda. Los muebles no elegidos por García Doménech para su uso personal ascendieron a un total de 24.426 reales y 17 maravedís. Aparte del collar como miembro de la Orden del Toisón de Oro, otros elementos llamativos que aparecieron fueron una portentosa colección de vinos compuesta por 650 botellas de vidrio y una surtida biblioteca de 379 libros. Los títulos inventariados nos informan de una persona de mentalidad práctica, muy interesada por los asuntos relacionados con la historia, la

\footnotetext{
${ }^{20}$ Diario de las discusiones y actas de las Cortes, Cádiz, Imprenta Real, 1811, t. V, p. 195

${ }^{21}$ El término afrancesado y su utilización por la historiografía ha generado un interesante debate. Además del artículo de Morange, conviene tener en cuenta las recientes contribuciones de PRO RUIZ, Juan: "Afrancesados: sobre la nacionalidad de las culturas políticas", en M. Pérez Ledesma y M ${ }^{a}$ SIERRA (eds.): Culturas politicas: teoría e historia, Zaragoza, Institución Fernando el Católico, 2010, pp. 205-231; RAMÓN SOLANS, Francisco Javier: "El legado historiográfico de Miguel Artola: afrancesados, josefinos, juramentados y colaboracionistas", Rolde. Revista de cultura aragonesa, no 124-125 (enero-junio 2008), pp. 4-11; y del mismo autor "En torno a la definición de afrancesados", en A. Ramos Santana y A. Romero Ferrer, Alberto (dirs.): Liberty, liberté, libertad: el mundo hispánico en la era de las revoluciones, Cádiz, Universidad de Cádiz, 2010, pp. 86-99.

22 MERCADER RIBA, Juan: “La desamortización española bajo José Bonaparte", en Actas de las I Jornadas de Metodología Aplicada a las Ciencias Históricas, Vigo, Universidad de Santiago de Compostela, 1975, pp. 83-96.
} 
legislación o la religión, pero no precisamente de un entusiasta de la philosophie ${ }^{23}$. Urquijo sólo pudo llevarse consigo algunos documentos personales, que después legaría a sus descendientes y acabarían en los fondos de la Biblioteca Nacional ${ }^{24}$

Ganada la guerra y animadas por la legislación represiva, pronto comenzaron a aparecer publicaciones que se dedicaron a atropellar a los josefinos valiéndose de las tesis conspiratorias, como la famosa El azote de los afrancesados y zeloso defensor de la libertad de la Patria, del mercedario calzado fray Manuel Martínez, en medio de una ofensiva política y cultural que se vería reforzada por el púlpito y el teatro ${ }^{25}$. Tachados y vituperados, los emigrados josefinos serían conocidos por la posteridad con el sonrojante epíteto de afrancesados.

\section{LA EMIGRACIÓN}

No resulta sencillo reconstruir la trayectoria biográfica de Urquijo en el exilio ${ }^{26}$, por lo que sólo daremos algunos datos generales Tras la derrota de Arapiles a finales de julio de 1812, siguió al rey José I en un peregrinaje a Valencia que se vieron obligadas a realizar unas veinte mil personas ${ }^{27}$. El 23 de noviembre José I regresó fugazmente a Madrid y Urquijo fue uno de los pocos que le acompañaron. El 17 de marzo de 1813 se perdió definitivamente la capital para la causa josefina y ya no se separó del hermano de Napoleón en su huida escalonada a Francia.

\footnotetext{
23 "Inventario de los bienes hallados en la casa que habitó don Mariano Luis de Urquijo". Año de 1813. Archivo particular de don José María de Urquijo y Olaso. Conste mi más sincero agradecimiento, tanto para él como para Alfonso Carlos Sáinz Valdivielso, por haberme facilitado la oportunidad de acceder a un documento tan interesante.

24 "Papeles varios de Mariano Luis de Urquijo". B(iblioteca)N(acional), mss. 7774.

${ }^{25}$ LÓPEZ TABAR, J.: Los famosos..., op. cit., pp. 115-116; y del mismo autor: "El exilio de los afrancesados. Reflexiones en torno al real decreto de 30 de mayo de 1814", Spagna contemporanea, no 16, 1999, pp. 7-21.

${ }^{26}$ Hace ya varios años M. Sáez presentó en Francia una tesina titulada "Mariano Luis de Urquijo, son séjour en France (1813-1817)" dirigida por el profesor Guinard, que Gérard Dufour cita en su Juan Antonio Llorente en France (1813-1820). Contribution a l'étude du Libéralisme chrétien en France et en Espagne, Genéve, Librairie Droz, 1982, p. 128, n. 97. Según me informó amablemente este autor, habría un ejemplar de la misma en el Institut d'Études Hispaniques, en París, pero los intentos por localizarla han sido hasta ahora infructuosos.

${ }^{27}$ FUENTES, Juan Francisco: "Afrancesados y liberales", en J. Canal (ed.): Exilios. Los éxodos políticos en la Historia de España. Siglos XV-XX, Madrid, Sílex, 2007, pp. 141-142.
} 
El fracaso de la batalla de Vitoria obligó a José I a atravesar los Pirineos, instalando el cuartel general en la localidad fronteriza de San Juan de Luz. Urquijo permaneció todo el verano de 1813 en Pau, colaborando en diversas labores de evacuación de los emigrados españoles, que llegarían a una cifra total de 4.172 personas $^{28}$ y cuya situación escapaba al control de las autoridades francesas, Escribió al duque de CampoAlange, embajador español en Francia, ordenándole que instara a la Junta de Socorros organismo creado por el ministerio de Estado francés y dotado con unos 200.000 francos mensuales de ayuda ${ }^{29}$ - a que aliviara sus penalidades. Mantuvo también constante correspondencia con Miguel José de Azanza, que estaba elaborando listas con los emigrados; sus gestiones personales posibilitaron que veinticuatro exiliados pudieran instalarse en el departamento de los Bajos Pirineos, siendo exceptuados de la orden de alejamiento de las fronteras ${ }^{30}$.

El 20 de octubre de 1813 Urquijo dirigió un correo al conde Otto de Mosley, ministro de Estado, en la que le informaba a que se encontraba en París junto con el marqués de Almenara, el chambelán del rey marqués de Arneva y el montero real y comandante del escuadrón de Caballería Fermín Droz ${ }^{31}$. Por aquellas fechas la capital francesa era un destino prohibido para la mayoría de los emigrados, que se hacinaban en los departamentos meridionales ${ }^{32}$. A pesar de la desgracia podía ser considerado un privilegiado.

El 11 de noviembre de 1813 se firmó el Tratado de Valençay, por el cual Napoleón devolvía a Fernando VII el trono español bajo diversas condiciones, entre las cuales figuraba expresamente -artículo 9- que todos los españoles adictos al rey José I verían reintegrados sus honores, derechos y prerrogativas, así como los bienes de los que se habían visto privados. Este punto fue ratificado en términos generales por el Tratado de París, que terminó rubricando el embajador Pedro Gómez Labrador el 20 de julio de 1814, en el que se establecía que ningún individuo sería molestado en su persona o bienes a causa

\footnotetext{
${ }^{28}$ Esta es la cifra que arroja el censo de refugiados, aunque el porcentaje real probablemente sería mayor. Ibídem, pp. 106-108. Otros hablan de doce mil familias en el exilio. BARBASTRO GIL, Luis: Los afrancesados. Primera emigración política del siglo XIX español (1813-1820), Alicante, Instituto de Cultura Juan Gil-Albert, 1993, p. 8.

${ }^{29}$ LÓPEZ TABAR, J., Los famosos..., op. cit., pp. 109-110.

30 Urquijo a Campo-Alange. Mortefontaine, 4-XI-1813. A(rchivo)H(istórico)N(acional), Estado, leg. 6779. MORANGE, Claude: Paleobiografía (1779-1817) del «Pobrecito bolgazán». Sebastián de Miñano y Bedoya, Salamanca, Ediciones Universidad, 2002 p. 303, n. 64.

${ }^{31}$ París, 20-X-1813. A(rchivo)H(istórico)N(acional), Estado, leg. 6779.

32 Hasta el 20 de marzo de 1814 las autoridades francesas no se mostraron flexibles en la concesión de permisos para que los emigrados pudieran ir a París. AYMES, Jean-René: Españoles en París en la época romántica (1808-1848), Madrid, Alianza Editorial, 2008, p. 46.
} 
de las opiniones políticas que hubiese mantenido durante el conflicto; el gobierno francés pretendía con ello que España admitiese a los emigrados ${ }^{33}$.

Entre los exiliados se generalizó la esperanza de que Fernando VII fuera clemente con los antiguos josefinos; la cascada de juramentos junto con sus respectivas exposiciones individuales que llegaron a Madrid dan buena prueba de ello. Urquijo fue de los que escribieron a Fernando VII. Había que recuperar unas relaciones clientelares que habían sido destruidas; era complicado, pero se trataba de la única vía posible para un regreso inmediato. Dirigió su carta al duque de San Carlos, que desde los tiempos del motín de Aranjuez había formado parte de la camarilla fernandina y que iba a ser nombrado ministro en $1814^{34}$. La complejidad de la situación no impidió que Urquijo se mostrara pundonoroso, tal vez en un exceso que habría de perjudicarle, pintándose como un español "reconocido á las honras de S. M. y á las distinciones con que me hallo condecorado en mi carrera".

Tampoco se mostró humillado con Fernando VII. Solicitó el perdón para los afrancesados recordando las proclamas de obediencia a las autoridades josefinas que había dictado durante su cautiverio en el castillo de Valençay. Es más: para Urquijo era los josefinos los españoles que habían seguido fielmente tales máximas, porque su objetivo era que España no fuese despezada y destruida por Napoleón ${ }^{35}$, lo que suponía una condena de la actitud de los insurgentes patriotas. Es más, le recordaba también que fue el mismo Deseado quien había rechazado el trono, tanto en Bayona como con su conducta observada en Valençay; los acontecimientos, en una combinación que "la prudencia humana jamas pudo prevér", fueron los que se impusieron a lo que parecía la cadena lógica de sucesos. Urquijo llamaba por último a detener "odios y persecuciones", provocados por "las pasiones inevitables en el calor de los partidos", y demandaba la protección y el amparo de los millares de refugiados españoles que había en Francia, especialmente de quienes habían servido a sus órdenes en el ministerio ${ }^{36}$.

No sabemos si era lo que pretendía, pero la exposición resultó un brindis al sol. Ni más ni menos que lo que sucedió con el resto, pues el real decreto de 30 de mayo de 1814 prohibió la entrada de los afrancesados en España. En cualquier caso evidenciaba que

\footnotetext{
${ }^{33}$ LÓPEZ TABAR, J.: Los famosos traidores..., op. cit., pp.126-127.

${ }^{34}$ LA PARRA, E.: “Los hombres...”, op. cit., pp. 136-138.

35 Hallamos similares expresiones en las reflexiones de otros afrancesados. Véase, por ejemplo, Memoria de D. Miguel José de Azanza y D. Gonzalo O'Farrill, sobre los hechos que justifican su conducta política, desde marzo de 1808 hasta abril de 1814, París, P. N. Rougeron, 1815, pp. 141-142.

36 París, 15-IV-1814. AHN, Estado, leg. 5244. Expediente de Mariano Luis de Urquijo. Debo las noticias sobre este documento a Juan López Tabar. Reproducido en ROMERO PEÑA, Aleix: "Peripecias de un afrancesado vasco: Mariano Luis de Urquijo", RIEV. Revista Internacional de Estudios Vascos, no 58, 2 (juniodiciembre 2013), en prensa.
} 
Urquijo tenía muchas cuentas que saldar. Para él, la guerra se reducía a la conducta que habían observado los distintos actores políticos en 1808; el resto sólo contribuía a inflar la inocencia o a cargar las culpas.

Tras el jarro de agua fría del decreto de 30 de mayo, a los afrancesados sólo les quedó recurrir a las autoridades del país de acogida, que pese a la caída de Napoleón y el regreso de los Borbones siguieron ocupándose de los emigrados españoles. ${ }^{37}$. El 8 de octubre de 1814 Louis de Jaucourt, ministro interino de Asuntos Exteriores, escribió a Talleyrand, que se hallaba entonces en el Congreso de Viena, diciéndole que había recibido a Urquijo, Azanza y O’Farrill, quienes le habían asediado con cartas y visitas para asegurarle que la Francia de la Restauración no tendría en ellos un enemigo: "la pitié seule parle en leur faveur", añadía ${ }^{38}$. Los emigrados afrancesados terminaron recibiendo el estatus de refugiado, con pequeñas ayudas económicas. Urquijo fue de los más favorecidos, recibiendo gracias a su anterior rango ministerial una pensión de mil francos anuales ${ }^{39}$.

El regreso de Napoleón durante los Cien Días sólo supuso un paréntesis para los emigrados españoles. No hemos encontrados indicios de ningún arrebato napoleónico en Urquijo; parece que la principal tarea que le ocupó en aquellos años, lastrados por la mala salud, fue dar a conocer su propia versión sobre la guerra. Para ello contó con la inestimable ayuda de Juan Antonio Llorente. Urquijo y Llorente coincidieron cuando el primero dirigió a la Secretaría de Estado; fue entonces el canónigo Llorente tradujo a iniciativa suya la obra del regalista portugués Antonio Pereira Demostraçao theologica, que acabaría secuestrada por la Inquisición en 1801. Volvieron a reencontrarse con José I y gracias a la protección de su poderoso amigo, Llorente acumuló varios cargos -director de bienes nacionales, comisario general de cruzada o consejero de Estado- hasta que finalmente se vio obligado a abandonar España, recalando en Burdeos, donde permaneció hasta que el 17 de febrero de 1814 fue autorizado su traslado a París ${ }^{40}$.

La colaboración entre ambos fructificó en las Memorias para la historia de la revolución española, una obra que Llorente compuso con la intención de mejorar su situación financiera y que fue publicada en castellano y en francés. La idea central de las Memorias es en esencia la misma que Urquijo había presentado en su exposición a Fernando VII. Los josefinos

\footnotetext{
${ }^{37}$ FUENTES ARAGONÉS, Juan Francisco: “Afrancesados...”, op. cit., p. 142.

38 "Sólo la piedad habla en su favor". Jaucourt a Talleyrand. París, 8-X-1814. Correspondance du comte de Jaucourt, ministre intérimaire des Affaires Étrangères avec le prince de Talleyrand pendant le Congrès de Viena, París, Plon, 1905, p. 25

${ }^{39}$ FERNÁNDEZ SIRVENT, Rafael: Francisco Amorós y los inicios de la Educación Física moderna. Biografía de un funcionario al servicio de Francia y España, Alicante, Publicaciones de la Universidad de Alicante, 2005, p. 153, n. 354.

40 Además del libro ya citado de Gérard Dufour, sobre la biografía de Llorente véase también FERNÁNDEZ PARDO, Francisco: Juan Antonio Llorente, español "maldito", Donostia-San Sebastián, 2001.
} 
siguieron escrupulosamente las instrucciones del Borbón y los verdaderos traidores fueron aquellos que se lanzaron a una lucha contra la voluntad del soberano. En esta vuelta de tuerca, se ensañaban especialmente con aquellos que en su momento aprobaron el cambio dinástico: desde consejeros a embajadores o ministros ${ }^{41}$.

Sobre la obra enseñorea, más que el espíritu de la venganza, el de la amargura, que es la sensación que arrojan los documentos expuestos. Al menos Urquijo hubo de aportar tres cartas, fechadas en 1808, y dirigidas a un amigo, el capitán general Gregorio García de la Cuesta, a quien después encontraremos comandando al ejército insurrecto de Castilla la Vieja. Esta colaboración se ocultó mediante un conocido procedimiento cervantino: Llorente explica a sus lectores que las misivas formaban parte de unos documentos que hallaron las tropas francesas al entrar en Valladolid, con lo que además introduce la percepción de que son materiales originales y que no han sido manipulados. A pesar del subterfugio, algún estudioso, sorprendido con el mutismo literario de Urquijo en el exilio, ha llegado a comentar que apadrinó de alguna manera la obra de Llorente ${ }^{42}$.

Que fuera Urquijo quien suministrase los documentos, tal vez modificándolos parcialmente, no les resta toda veracidad. Se puede contrastar la noticia de que Gregorio García de la Cuesta encomendase a Urquijo que avisara a Fernando a su paso por Vitoria de lo que tramaban los franceses, pues él mismo lo contaría en plena guerra, escribiendo que informó al gobernador de Santander:

un vecino de aquella ciudad [Santander], cuyo nombre merece ser conocido por su decidido valor y patriotismo, pero que hoy conviene reservar por consideraciones muy importantes, llevase una carta que entregase en mano propia de S. M. en Vitoria, manifestándole cuánto importaba salvar su augusta persona y facilitándole los medios para lograrlo ${ }^{43}$.

Pero Cuesta no sólo silenció el nombre de aquel vecino "por consideraciones muy importantes", sino que también sustituyó el nombre de la ciudad a la que realmente remitió la carta, Bilbao, por Santander. Paradójicamente alababa a alguien cuyo nombre no podía

\footnotetext{
${ }^{41}$ DUFOUR, G.: Juan Antonio Llorente..., op. cit., pp. 57 y 70-73. Entre los atacado se hallan viejos conocidos de Urquijo, tanto amigos como enemigos, que habían prestado juramento de fidelidad a José I: Pedro Cevallos, José García de León y Pizarro, Pedro Gómez Labrador -Llorente incluyó de él una carta dirigida a Urquijo-, Escóiquiz, el mismo duque de San Carlos, etc.

${ }^{42}$ Véase JURETSCHKE, Hans: Los afrancesados en la Guerra de la Independencia, Madrid, Rialp, 1962, pp. 208-ss.

${ }^{43}$ GARCÍA de la CUESTA, Gregorio: Manifiesto que presenta á la Europa el Capitán general de los Reales Egércitos Don Gregorio García de la Cuesta de la conducta Sobre sus operaciones militares y políticas desde el mes de junio de 1808 hasta el día 12 de agosto de 1809 en que dejó el mando del egército de Extremadura, Palma de Mallorca, Imprenta de Miguel Domingo, 1812, pp. 2-3, n. 2 .
} 
mencionar, porque había demostrado aquello de lo que según la propaganda insurgente carecían los de su bando: "decidido valor y patriotismo".

Las cartas reproducidas traslucen el ritmo vertiginoso de los acontecimientos de la primavera de 1808 en apenas unas semanas. La primera, del 13 de abril, es el momento del desastre, del viaje a Bayona que precipitará lo que ha de venir. La segunda, del 8 de mayo, refleja la calma que sucede a la tormenta. Son momentos de esperanza y de temor; si por un lado Urquijo evalúa de manera positiva los aspectos que aparecen con el nuevo escenario -la posibilidad de que se dictaran "leyes y pactos que creasen y asegurasen a esta nación su felicidad interior"-, por otro confiesa su prevención sobre el "carácter nacional de ferocidad y barbarie, que por efecto de una vil esclavitud y negra superstición" se habían forjado los españoles, el cual era muy probable que terminara echando a perder todas las facetas ilusionantes ${ }^{44}$. La última, del 5 de junio, supone la toma de partido. Urquijo se posiciona con los Bonaparte por confianza y miedo a la vez: confianza despertada por la disposición de implantar una Constitución en España y miedo provocado por las amenazas de conquista e invasión del país.

Las Memorias concitaron en su época gran interés y fueron consultadas entre otros por Dominique de Pradt, el conde de Toreno, Karl Marx o el látigo de los afrancesados, fray Manuel Martínez. Los hechos que llevarían al famoso estallido popular de los levantamientos del 2 de mayo parecían poder proyectarse en los movimientos de una persona que, en su contingencia individual, sólo se representaba a sí misma. Jovellanos, por ejemplo, tuvo la perspectiva opuesta de los hechos. El ilustrado asturiano comentaba a su amigo Cabarrús, josefino de primera hora, le diría que los insurrectos luchan "por su religión, por su constitución, por sus leyes, sus costumbres, sus usos, en una palabra, por su libertad" ${ }^{\prime 4}$. Diferentes situaciones, distintas versiones; todas incompletas. Si Urquijo no supo calibrar la respuesta popular a las abdicaciones de Bayona, Jovellanos ignoraba todo lo referido a los movimientos políticos de Fernando y su séquito.

Llorente ampliaría posteriormente la versión de Urquijo convirtiéndolo en una especie de mártir laico, un "verdadero filósofo cristiano" según unos versos que colocó en la lápida de aquel, en referencia a los ataques de los reaccionarios. En su famosísima Historia crítica de la Inquisición, que apareció por primera vez, en francés, después de la muerte de Urquijo, realizaba una apasionada semblanza de su antiguo amigo, haciendo un breve recorrido biográfico. Según Llorente, Urquijo quiso ver en Fernando la posibilidad

${ }^{44}$ Urquijo a Cuesta. Bilbao, 8-V-1808. NELLERTO: Memorias..., op. cit., t. II, no LIX, pp. 181-184.

45 Jovellanos a Cabarrús. Jadraque, ¿?-VIII-1808. JOVELLANOS, Gaspar Melchor de, Obras completas, edición, introducción y notas de María Teresa Caso Machiado y Javier González Santos, Oviedo, Instituto Feijoo de Estudios del Siglo XVIII, 1999, t. IV, no 1.741, p. 563. 
de emprender las reformas necesarias para la regeneración del reino. Tras el curso inexorable de los acontecimientos, apoyó a José I para evitar las calamidades que se cernían sobre España: las revueltas populares, la profanación de los templos, el incendio de las casas, la ruina de las familias... En definitiva, "l'arracher au fléau de la guerre civile et de la guerre étrangère; maintenir l'integrité des frontières, et lui conserver le haut rang que l'honneur national réclamait" ${ }^{46}$. Todo ello gracias a su patriotismo, su filantropía y su espíritu de sacrificio.

Llorente anunciaba la inminente aparición de un elogio que fue publicado en 1820. Su autoría está discutida: si bien en la portada se presenta como autor Antonio de Beraza - un posible pariente de Urquijo que durante el reinado de José I dirigió la administración de Correos y la Imprenta General-, otros testimonios señalan la afamada pluma de Manuel Silvela ${ }^{47}$. El libro se enmarca en el género literario que en el siglo XVIII había tomado por objeto la alabanza de las virtudes de "los grandes hombres", es decir, de aquellos que habían destacado en algo útil o agradable, y que pretendía crear un pabellón laico de la memoria ${ }^{48}$. Su contenido profundiza en los temas apuntados por Llorente y, salvo algunas referencias que parecen haber sido tomadas directamente de Urquijo, no aporta nada nuevo.

\section{CONCLUSIONES}

A la altura de 1820, tres años después de la muerte de Urquijo, su recuerdo histórico ya había quedado difuminado por todo lo que se había escrito sobre él. En España la propaganda lo había convertido en un enemigo de la religión, un pernicioso filósofo que había traicionado a su país. En la colonia de emigrados en Francia se estaba imponiendo en cambio la imagen del mártir laico que se había sacrificado por patriotismo. Conviene tener en cuenta que su desaparición había tenido lugar en unos momentos difíciles para los exiliados, justo cuando arreciaba la ofensiva contra ellos del diputado ultrarrealista JeanClaude Clausel de Cousserges. Pero no todos estuvieron conformes con la edulcoración de su figura histórica. Aparte de la ironía que despiertan en Andrés Muriel las alabanzas grabadas en su lápida, Francisco Amorós se refirió a él con denuestos, colocándole en su

46 "Extirpar la amenaza de la guerra civil y extranjera, asegurar la integridad de las fronteras y mantener a España en el alto rango que el honor nacional reclamaba". LLORENTE, Juan Antonio, Histoire critique de l'Inquisition en Espagne, depuis de l'époque de son établissement par Ferdinand V jusqu'au règne de Ferdinand V, París, Treuttel et Würtz, 1818, p. 111. 47 SILVELA, Francisco Agustín: Obras póstumas, Madrid, Francisco de Paula Mellado, 1845, pp. XXII-XXIII. Jean-René Aymes apoya esta autoría recordando que Silvela también escribió una Elegía a la muerte de Moratín. Véase Españoles en París..., op. cit., p. 160.

${ }^{48}$ DOSSE, François: El arte de la biografía, México D. F., Universidad Iberoamericana, 2007, pp. 150-151. 
Dictionnaire bajo el epíteto de "farolón" y despachándolo con calificativos tales como “embustero, corrupto, fatuo, orgulloso, cobarde, egoísta, miserable, fantasmón y mal patricio" $"$.

Por supuesto que ambos retratos empobrecen una biografía compleja y contradictoria. La filantropía no casa muy bien con ciertas tareas que asumió Urquijo durante la guerra. Según el Elogio, Urquijo fue un firme defensor de la "seguridad individual" y propuso a José I la supresión del ministerio de la Policía por ser "incompatible con las ideas liberales de V. M., con el honrrado carácter español, y tan tremendo como la Inquisicion misma" ${ }^{, 50}$. Sin pretender relacionar a Urquijo con la violencia desatada por las tropas francesas, cuantitativa y cualitativamente mayor que en la emprendida por la Monarquía josefina ${ }^{51}$, no podemos tampoco dejar de señalar su participación en las medidas represivas en calidad de ministro secretario de Estado -entre cuyas funciones se encontraba la de refrendar con su firma todos los actos del gobierno josefino-.

Sus contemporáneos no pasaron por alto este aspecto. El 17 de febrero de 1809 José I aprobó un reglamento para la entrada, salida y circulación de personas por Madrid, que fijaba un control excepcional de los forasteros que iban a la capital. El decreto fue reproducido en el folleto titulado Gritos de Madrid cautivo a los pueblos de España y su autor, reparando en la preceptiva firma de Urquijo, añadía entre paréntesis: “oprobio eterno del nombre español" 52 . Tampoco se olvidaron fácilmente de su rápido ennoblecimiento, por más que el Elogio asegurara que "desearía no tener las dos cruces [de la Orden de San Juan de Malta y la Orden de Carlos III] con que se hallaba para salir del ministerio vestido de paisano" "53. Aparte de las órdenes ya mencionadas, Urquijo fue recibido como caballero en la y la Orden Real josefina -la Berenjena-, además de habérsele concedido el collar del Toisón de oro. El autor del Elogio se siente obligado a precisar en una nota que devolver tales condecoraciones hubiera resultado afectado e impolítico.

\footnotetext{
49 MURIEL, Andrés: Historia del reinado de Carlos IV, edición y estudio preliminar de Carlos Seco Serrano, Madrid, Atlas, 1959, t. I, p. 215. Sobre los ataques de Amorós, véase FERNÁNDEZ SIRVENT, R., Francisco Amorós..., op. cit., p. 114, n. 239.

${ }^{50}$ BERAZA, A.: Elogio..., op. cit., pp. 67-68.

51 PIQUERAS DÍAZ, Antonio J.: "José I, maléfico o divino", en E. La Parra (coord.), La imagen del poder. Reyes y regentes en la España del siglo XIX, Madrid, Síntesis, 2011, pp. 104-105.

${ }^{52}$ El folleto se encuentra en la B(iblioteca) V(alenciana), Colección V alencia, signatura CV/5419.

${ }^{53} \mathrm{El}$ texto se remite a la época de Carlos IV. BERAZA, A.: Elogio..., op. cit p. 64.
} 
Para Isabel Burdiel los individuos son una colección de fragmentos y las biografías un juego de interpretaciones que ha de tener en cuenta la contingencia radical de los agentes sociales ${ }^{54}$. En este sentido, tan peligroso resulta para el análisis histórico detenerse exclusivamente en un fragmento que en otro. Aunque las observaciones de Urquijo y su entorno en el exilio resulten de gran interés históricos, debemos ser precavidos con su uso.

${ }^{54}$ BURDIEL, Isabel: "La dama de blanco. Notas sobre la biografía histórica", en I. Burdiel y M. Pérez Ledesma (eds.): Liberales, agitadores y conspiradores, Madrid, Espasa, 2000, pp. 17-47. 